\title{
Integrated systems and robotics in forensics
}

Sezonova Iryna ${ }^{1}$

Sezonov Victor $^{2}$
${ }^{I}$ Kharkiv National University of Radio Electronics, Nauki Ave. 14, Kharkiv, 61166,Ukraine, iryna.sezonova@nure.ua

${ }^{2}$ Kharkiv Research and Forensic Center, Kovtuna st.32, Kharkiv, 61036,Ukraine,sv26031985@gmail.com

\begin{abstract}
The article reviews the problematic aspects of the development and improvement of forensic activities. The authors proves the necessity of forming a new separate branch of criminalistic technique. The authors proposes the new termin - "The Criminalistic robotechnology" - for it. Along with the effective use of existing tools and methods of application of special knowledge in the detection and investigation of crimes, also addresses the problem of developing new, based on modern technologies.
\end{abstract}

Keywords: innovative technologies; forensic examination; forensic activities; criminalistic robotechnology; criminalistic technique; robocop.

\section{INTRODUCTION}

The latest achievements of scientific and technological progress have made it possible to improve the work of forensic experts so much that the solution of many tasks of forensic examination without the use of modern information technologies has become impossible. Currently, work is underway to create a collection of digital computer models of objects of technical and forensic research of documents. Automated workstations for forensic experts of various expert specialties (trasologist, ballista, economist, phonoscopist, psychologist, etc.), new devices and complexes of functional devices for research and recording of evidence, developed techniques for the study of new objects of forensic examination, created various information retrieval systems and databases. The possibilities of forensic biological research using modern advances in mathematical modeling have been greatly expanded. At present, in practice, robots are used that allow recognizing explosive devices, penetrate into small rooms with video surveillance function, and replace the nonmalfunctioning process.

\section{BASIC TASKS OF INTELLIGENT CONTROL SYSTEMS FOR MANIPULATIONS}

The process of development of forensic expertise is directly dependent on the needs of investigative and judicial practice. It determines the relevance of various scientific studies necessary to establish circumstances relevant to the investigation of crimes. The level of knowledge in various fields of science and the development of general methods of cognition, on the one hand, and changes in the forms of criminal procedure, the role of forensic science in this process, and the norms governing its activities affect the development of forensic science and the degree to which innovative technologies are used in forensic research - with another.
In Ukraine, the Evrika forensic examination support system has been developed to conduct examination of cable products in the wake of reflows. Flexible systems and databases have been created - Dagger _ (cold steel examination), Baleks (forensic ballistic examination), Narcoex (for the study of narcotic substances), FARA (for the study of headlights of vehicles and their fragments) other. The use of innovative technologies allowed expanding the possibilities of technical and forensic research of documents, increasing the reliability and scientific level of research in solving most expert problems. For example, using metallographic microscopes with a 500-fold magnification, equipped with digital photo or video, it became possible to establish the sequence of printing texts and characters even in the absence of areas of intersection. The possibilities of forensic biological research using modern advances in mathematical modeling have been greatly expanded.

A forensic environmental assessment is also in the process of being formed today. Variants of classification of research objects depending on the place of the disaster (land, water, air), or on the type of catastrophes themselves (explosion, flood) are proposed. Recently, forensic environmental assessments are being carried out more and more often. They relate mainly to events such as the release of harmful substances into the environment and pollution of rivers and water bodies. More and more attention is being paid to the robots used in forensic activities. We offer our own version of the classification of robots by their role in the fight against crime: a) robots and robotic systems, functionally designed for the prevention, suppression, prevention of criminal attacks and administrative offenses; b) robots and robotic systems, functionally designed to study the situation of crimes committed and crime scenes.

\section{CONCLUSION}

We believe that "forensic robotics" is a branch of forensic technology that studies the practice of using special robotics in the process of suppressing, preventing, disclosing, investigating, preventing crimes and administrative offenses in order to develop recommendations on the design and modernization of robotic tools, as well as improving techniques, methods and methods of using these tools in order to optimize the establishment of objective truth in the case.

\section{REFERENCES}

[1] Hollegie, J.H.J. Basic Knowledge, document recognition, 2009, 232 p.

[2] Kelly, J.S., Lindblom, BS. Scientifi c Examination of Questioned Documents, Second Edition, CRC Press, 2006, 464 p.

[3] E. N. Bystryakov, I. V. Usanov Forensic robotics as a new branch of forensic technology.Research Journal №1(7) 2016 Criminal procedure, Criminalistics and Judicial examination Problems, c.17-22 